\title{
Stress hormone release is a key component of the metabolic response to lipopolysaccharide: studies in hypopituitary and healthy subjects
}

\author{
Ermina Bach ${ }^{1,2}$, Andreas B Møller ${ }^{1,2}$, Jens O L Jørgensen ${ }^{1,2}$, Mikkel H Vendelbo ${ }^{1,3}$, \\ Niels Jessen ${ }^{1,2}$, Steen B Pedersen 1,2, Thomas S Nielsen ${ }^{1,2,4}$ and Niels Møller ${ }^{1,2}$ \\ ${ }^{1}$ Medical Research Laboratories, Department of Clinical Medicine, Incuba/Skejby, Aarhus N, Denmark, \\ ${ }^{2}$ Department of Endocrinology and Internal Medicine, ${ }^{3}$ Department of Nuclear Medicine \& PET-Centre, \\ Aarhus University Hospital, Aarhus C, Denmark, and ${ }^{4}$ The Novo Nordisk Foundation Centre for Basic Metabolic \\ Research, Section on Integrative Physiology, Faculty of Health and Medical Sciences, University of Copenhagen, \\ Copenhagen, Denmark
}

\author{
Correspondence \\ should be addressed \\ to E Bach \\ Email \\ Bach.Ermina@gmail.com
}

\begin{abstract}
Objective: Acute and chronic inflammatory and metabolic responses are generated by lipopolysaccharide (LPS) during acute illness and in the pathogenesis of the metabolic syndrome, type 2 diabetes and cardiovascular disease, but whether these responses depend on intact pituitary release of hormones are not clearly identified. We compared the metabolic effects of LPS in hypopituitary patients (HPs) (in the absence of growth hormone (GH) and ACTH responses) and healthy control subjects (CTR) (with normal pituitary hormone responses).

Design: Single-blind randomized.

Methods: We compared the effects of LPS on glucose, protein and lipid metabolism in eight HP and eight matched CTR twice during 4-h basal and 2-h hyperinsulinemic-euglycemic clamp conditions with muscle and fat biopsies in each period during infusion with saline or LPS.

Results: LPS increased cortisol and GH levels in CTR but not in HP. Also, it increased whole-body palmitate fluxes (3-fold) and decreased palmitate-specific activity (SA) $40-50 \%$ in CTR, but not in HP. G(0)/G(1) Switch Gene 2 (GOS2 - an inhibitor of lipolysis) adipose tissue (AT) mRNA was decreased in CTR. Although LPS increased phenylalanine fluxes significantly more in CTR, there was no difference in glucose metabolism between groups and intramyocellular insulin signaling was unaltered in both groups.

Conclusions: LPS increased indices of lipolysis and amino acid/protein fluxes significantly more in CTR compared with HP and decreased adipocyte G0S2 mRNA only in CTR. Thus, in humans intact pituitary function and appropriate cortisol and $\mathrm{GH}$ release are crucial components of the metabolic response to LPS.
\end{abstract}

\section{Introduction}

Lipopolysaccharide (LPS, endotoxin) is an important outer membrane constituent of Gram-negative bacteria with pleiotropic actions, including activation of cytokines; $(1,2)$; LPS is an important mediator of Gram-negative sepsis (3) and chronic overexposure to LPS, presumably derived from intestinal microbiota, may lead to a state (c) 2016 European Society of Endocrinology Printed in Great Britain of constant low-grade inflammation, which is associated with obesity, dyslipidemia, metabolic syndrome, insulin resistance, diabetes and subsequent cardiovascular risk $(4,5,6,7,8)$.

After LPS administration, a biphasic response in glucose uptake is observed in humans with an early

Published by Bioscientifica Ltd. 
period of increased insulin sensitivity followed by insulin resistance $(9,10,11,12,13,14,15)$. The underlying mechanisms are not clear and it is uncertain whether important intracellular mediators of insulin signaling $(16,17,18,19)$.

It has been reported that LPS administration in a human model during the initial phase of sepsis increases whole-body protein breakdown and release of amino acids from skeletal muscle and decreases plasma amino acid concentrations and protein synthesis $(13,20)$, but again the underlying signaling mechanisms are uncertain $(21,22)$.

A number of studies show that LPS administration increases lipolysis in humans $(23,24)$. Adipocyte lipolysis in humans is mediated by the two major lipases - adipose triglyceride lipase (ATGL) and hormone-sensitive lipase (HSL) $(25,26,27)$. LPS-induced lipolysis in murine and human adipocytes has been shown to involve increased activity of HSL and ATGL $(28,29,30)$.

LPS administration evokes generalized release of proinflammatory cytokines and these - in particular TNF- $\alpha$ and IL- 6 - mimicking the response to infection, induce insulin resistance and increased lipolysis in humans $(31,32)$. However, LPS acting through a number of cytokines also activates the hypothalamopituitary axis and stimulates the release of stress hormones (cortisol and GH) into the blood (33, 34, 35); cortisol and GH generate insulin resistance and lipolysis $(34,35,36,37,38)$ and glucocorticoids generate muscle loss (39), whereas GH in general conserves protein (37).

Thus, LPS invariably generates release of both cytokines and pituitary hormones and it is uncertain to which extent the metabolic actions of LPS are intrinsic or caused by cortisol and GH in humans. This study was designed to compare the metabolic effects of LPS in hypopituitary patients (HPs) (in the absence of ACTH and GH responses) and healthy volunteers (CTR) (with normal pituitary stress hormone responses).

\section{Subjects and methods}

\section{Subjects and design}

Eight male HP and eight age- and gender-matched CTR, $57 \pm 4$ years of age, were included in the study after oral and written informed consent was obtained. All CTR and HPs were healthy (aside from pituitary deficiencies) and did not receive other medications that may influence the results. This was confirmed during a medical interview, and normal blood test screening and physical examination were present. Body mass index of CTR was slightly lower (CTR: $26 \pm 1 \mathrm{~kg} / \mathrm{m}^{2}, \mathrm{HP}: 28 \pm 1 \mathrm{~kg} / \mathrm{m}^{2}$, $P=0.051)$ compared with HP.

During the study period, seven patients underwent operation for nonfunctioning pituitary adenoma and one patient for craniopharyngioma and all patients developed panhypopituitary insufficiency. GH deficiencies were confirmed with plasma IGF-1 concentration below normal and with a subnormal peak plasma GH concentration during an insulin hypoglycemia stimulation test. Pituitaryadrenocortical function was estimated with insulin hypoglycemia stimulation test and ACTH stimulation test. Determination of plasma concentration of total thyroxine was used for assessing thyroid function and plasma levels of testosterone were used for assessment of gonadal function. All patients received substitution therapy with hydrocortisone, thyroxine, testosterone and GH. In addition, one patient received desmopressin therapy and one patient received treatment with fludrocortisone. Average treatment length was 9 years (range between 4 and 16 years). The aim of the treatment was to ensure that the hormone levels were approximately in the normal range.

The study was approved by the Central Denmark Region Ethics Committee (M-2010-0076), in accordance with the Declaration of Helsinki. The study protocol was registered at www.clinicaltrials.gov (NCT01452958).

Both HP and CTR were studied on two occasions separated by a minimum of 1 month: once with LPS infusion and once with placebo (isotonic saline) infusion in a single-blind random manner from $t=0-360 \mathrm{~min}$. The subjects reported to the laboratory at $0700 \mathrm{~h}$ after an overnight fast. Vigorous physical exercise was not allowed for 2 days before participating in the study. HPs excluded the intake of $\mathrm{GH}$ and desmopressin medication on the penultimate day before the study and hydrocortisone and fludrocortisone were discontinued on the study day. HP received intravenous (iv) hydrocortisone $80 \mathrm{mg}(13 \mathrm{mg} / \mathrm{h})$ continuously during the experiment $(t=0-360 \mathrm{~min})$ to avoid acute cortisol deficiency. This high dosage was based on pilot experiments with lesser doses which induced signs of cortisol deficiency (low blood pressure, nausea, vomiting). A total of three iv catheters were inserted: one cubital catheter, used for infusion of isotonic saline, metabolite tracers, insulin, glucose and LPS; one in a heated dorsal hand vein for sampling of arterialized blood; and one retrogradely inserted into contralateral cubital vein for deep venous blood sampling. Venous occlusion plethysmography was used to determine forearm blood flow.

LPS (USP Endotoxin (LOT G3E069), The United States Pharmacopeial Convention, Inc., Rockville, MD, USA) was diluted in isotonic saline and administered 
continuously over $360 \mathrm{~min}(0.06 \mathrm{ng} / \mathrm{kg} / \mathrm{h})$. The first participant who received LPS, infusion rate $0.1 \mathrm{ng} / \mathrm{kg} / \mathrm{h}$ and administered continuously over $6 \mathrm{~h}$, was excluded from the study because of side effects - intense shivering, nausea, myalgia, high temperature and headache - and the dose was subsequently reduced to $0.06 \mathrm{ng} / \mathrm{kg} / \mathrm{h}$.

The study consisted of a $240 \mathrm{~min}$ basal period ('basal'), followed by a $120 \mathrm{~min}$ hyperinsulinemic-euglycemic clamp period ('clamp'). Infusion rates of insulin (Insulin Actrapid; Novo Nordisk) were $1.0 \mathrm{U} / \mathrm{kg} / \mathrm{min}$ iv. Systemic plasma glucose was clamped at $5 \mathrm{mmol} / \mathrm{L}$ by a variable infusion of $20 \%$ glucose and arterial plasma glucose concentrations were measured at least every $10 \mathrm{~min}$ (Beckman Instruments, Palo Alto, CA, USA).

\section{Tracer infusions and kinetics}

The chemical compounds ${ }^{15} \mathrm{~N}$-phenylalanine was used as an amino acid tracer and ${ }^{13} \mathrm{C}$-urea (Cambridge Isotope Laboratories, Andover, MA, USA) was used to estimate ureagenesis. A primed continuous infusion of ${ }^{15} \mathrm{~N}$-phenylalanine (prime $0.75 \mathrm{mg} / \mathrm{kg}$, infusion rate: $0.75 \mathrm{mg} / \mathrm{kg} / \mathrm{h}$ ) was started at $t=0$ and maintained until termination of the study. Wholebody phenylalanine and urea flux $(\mathrm{Q})$ and regional phenylalanine kinetics were calculated as described previously $(32,33,34)$.

Albumin-bound $[9,10-3 \mathrm{H}]$ palmitate (GE) was infused from $t=180-240 \mathrm{~min}$ and again from $t=300$ to $360 \mathrm{~min}$. Blood samples for measurements of palmitate concentration and SA were obtained before infusion and after 40,50 and $60 \mathrm{~min}$ of the infusion period by HPLC using [2H31] palmitate as internal standard. Palmitate was analyzed in triplicate during steadystate, and palmitate flux $(\mu \mathrm{mol} / \mathrm{min})$ was calculated as $[9,10-3 \mathrm{H}]$ palmitate infusion rate divided by the steadystate palmitate SA (35).

During the entire experiment $(\mathrm{t}=0-360 \mathrm{~min})$, primed, continuous infusions of [3-3H]-glucose (bolus $20 \mu \mathrm{Ci}$, $0.12 \mu \mathrm{Ci} \times \min -1$; NEN Life Science Products, Boston, MA, USA) were performed. To minimize rapid dilution of the $[3-3 \mathrm{H}]$-glucose during the clamp, $[3-3 \mathrm{H}]$-glucose was added to the infused glucose $(100 \mu \mathrm{Ci}$ [3-3H] glucose $/ 500 \mathrm{~mL} 20 \%$ glucose). Glucose rates of appearance (Ra) and disappearance (Rd) were estimated by Steele's equation (40).

Endogenous glucose production (EGP) equals Ra of glucose under basal conditions, and during the clamp EGP was calculated by subtracting mean rate of exogenous glucose from glucose Ra.

\section{Muscle biopsies}

Muscle biopsies were obtained under local anesthesia from lateral vastus muscles once during the basal $(t=120 \mathrm{~min})$ and once during the clamp ( $t=270 \mathrm{~min})$. Biopsies were cleaned immediately, snap-frozen in liquid nitrogen and stored at $-80^{\circ} \mathrm{C}$ until analyzed. Muscle biopsies were homogenized in an ice-cold buffer using a polytron blender. Insoluble materials were removed by centrifugation at $16000 \mathrm{~g}$ for $20 \mathrm{~min}$ at $4^{\circ} \mathrm{C}$.

\section{Western blotting}

Western blotting analyses were used to assess protein and phosphorylation levels of various proteins. Control for equal loading was performed using the stain-free technology (41).

Antibodies to Akt (no. 3063), AS160 (no. 2447), GS (no. 3886), GSK-3-alpha/beta (no. 5676), mTOR (no. 2972), 4E-BP1 (no. 9644), S6 (no. 2217) and phosphospecific antibodies Akt Thr ${ }^{308}$ (no. 9275), Akt Ser ${ }^{473}$ (no. 9271), AS160 $\mathrm{Thr}^{642}$ (no. 4288), AS160 Ser ${ }^{588}$ (no. 8730), phosphorylated Akt substrate sites PAS (no. 9611), GS Ser ${ }^{641}$ (no. 3891) and GSK-3-alpha/beta phospho S21/9 (no. 9331), p-mTOR $\operatorname{Ser}^{2448}$ (no. 2971), p-4E-BP1 Thr37/46 (no. 2855) and p-S6 (no. 4858) were from Cell Signaling Technology.

When possible phosphor blots were stripped and reprobed using alternative phosphor antibodies or antibodies against the unphosphorylated form of the protein.

AT biopsies and isolation of mRNA and real-time PCR analysis were performed as described previously (30).

The following primer pairs were used:

Perilipin: GGA GCG AGG ATG GCA GTC AAC and TCT GGA AGC ATT CGC AGG T

HSL: GAA GGC GGC ACG GAC GCC and GCT GGT GCG GCG GGA CAC

CIDEA: CGGCTGCCTTAACGTGAA and AGATGAGAAACTGTCCCATCA

\$2 Microglobulin: GAGGCTATCCAGCGTACTCC and AATGTCGGATGGATGAAACCC

ATGL: ACCTCAATGAACTTGGCACC and CAACGCCACGCACATCTA

GOS2: CGA GAG CCC AGA GCC GAG ATG and AGC ACC ACG CCG AAG AG

\section{Statistical analysis}

Data are presented as mean \pm S.E.M. Statistical analysis was performed using two-way (TW) repeated measures 
analysis of variance (ANOVA) as primary analysis and paired $t$-tests as post hoc analysis. All ANOVA results refer to (i) an overall main effect of LPS vs placebo, (ii) an overall insulin/clamp/time effect and (iii) LPS - insulin/ time interaction; in addition, we have given $P$ values for post hoc paired $t$-tests comparing the effect of LPS vs saline under a single treatment condition (basal or clamp). We compared LPS effects in the two groups (CTR and HP) using $t$-tests of delta mean values (LPS placebo) under a single treatment condition. Normal distribution was assessed by inspection of QQ plots and Wilcoxon signedrank tests were used to test not normally distributed data.

\section{Results}

There were no serious adverse side effects apart from one CTR receiving LPS, who experienced shivering, dizziness, fever, nausea, myalgia and headache, and whose experiment was interrupted at the beginning of the clamp.

Characteristics of the volunteers and arterialized hormone levels are given in Table 1. TW ANOVA for repeated measurements showed no overall LPS effect on mean blood pressure and temperature in HP. In CTR, mean blood pressure was not affected by LPS, but a paired $t$-test showed a trend toward temperature increase $\left(36.3 \pm 0.1^{\circ} \mathrm{C}\right.$ (placebo) vs $36.9 \pm 0.3^{\circ} \mathrm{C}$ (LPS), $P=0.051$ ) during the clamp. Four of the CTR subjects felt cold and had shivering (two of them had fever) and one was trembling (without feeling cold) most noticeably during the last $2-3 \mathrm{~h}$ of the experiment. HP had no symptoms. Heart rate increased during the LPS infusion in both CTR and HP.
Insulin levels decreased similarly (basal: $P=0.723$; clamp: $P=0.133$ ) during LPS infusion in both groups; CTR: basal period $23 \pm 3$ (placebo) vs $18 \pm 3 \mathrm{pmol} / \mathrm{L}$ (LPS) and clamp $380 \pm 21 \mathrm{pmol} / \mathrm{L}$ (placebo) vs $294 \pm 17 \mathrm{pmol} / \mathrm{L}$ (LPS), $P<0.001$; patients: basal period $27 \pm 5 \mathrm{pmol} / \mathrm{L}$ (placebo) vs $24 \pm 6 \mathrm{pmol} / \mathrm{L}$ (LPS) and clamp $412 \pm 28 \mathrm{pmol} / \mathrm{L}$ (placebo) vs $362 \pm 21 \mathrm{pmol} / \mathrm{L}$ (LPS), $P=0.011$.

Glucagon was not affected by LPS in the two groups.

Overall TW ANOVA for repeated measurements revealed a main LPS effect that increased cortisol levels $(P<0.001)$ in CTR (Table 1), and the difference was significant both in basal period $(P=0.017)$ and during the clamp $(P=0.002)$. Cortisol levels in HP remained unaltered.

In CTR GH levels were increased by LPS, and post hoc testing showed significance during the basal $(P=0.017)$ and borderline significance during the clamp period $(P=0.077)$. GH levels in the HP patients were undetectable.

Lactate concentrations were not affected by LPS in the two groups (Table 1).

\section{Amino acid metabolism}

Overall TW ANOVA for repeated measurements showed a main LPS effect $(P<0.001)$ to increase phenylalanine flux in CTR (Fig. 1A and Table 2), and post hoc tests revealed significant effects both during the basal $(P=0.026)$ and the clamp $(P<0.001)$ periods. LPS infusion also increased phenylalanine fluxes $(P=0.030)$ (Fig. $1 \mathrm{~B}$ and Table 2$)$ in HP, although post hoc showed only borderline significance: $P=0.063$ (basal) and $P=0.078$ (clamp). LPS decreased phenylalanine arterial enrichment in CTR (main effect: $P<0.001$, Table 2), and post hoc testing revealed significance in both periods (basal: $P=0.031$, clamp: $P<0.001$ ). There was only a trend toward a decreased enrichment in HP

Table 1 The characteristics of healthy volunteers (CTR) and hypopituitary patients (HP) and arterial hormone levels.

\begin{tabular}{|c|c|c|c|c|c|c|c|c|}
\hline & \multicolumn{4}{|c|}{ CTR } & \multicolumn{4}{|c|}{ HP } \\
\hline & \multicolumn{2}{|c|}{ Basal } & \multicolumn{2}{|c|}{ Clamp } & \multicolumn{2}{|c|}{ Basal } & \multicolumn{2}{|c|}{ Clamp } \\
\hline & Placebo & LPS & Placebo & LPS & Placebo & LPS & Placebo & LPS \\
\hline Mean BP $(\mathrm{mmHg})^{\circ}$ & $103 \pm 3$ & $104 \pm 3$ & $101 \pm 2$ & $102 \pm 4$ & $112 \pm 4$ & $109 \pm 3$ & $105 \pm 2$ & $103 \pm 3$ \\
\hline $\mathrm{HR}$ (beat/min) ${ }^{\circ}$ & $61 \pm 4$ & $64 \pm 4$ & $65 \pm 5$ & $74 \pm 5 *$ & $53 \pm 4$ & $55 \pm 4$ & $55 \pm 4$ & $64 \pm 5^{*, \#, \dagger}$ \\
\hline Temperature $\left({ }^{\circ} \mathrm{C}\right)^{\circ}$ & $36.1 \pm 0.1$ & $36.1 \pm 0.2$ & $36.3 \pm 0.1$ & $36.9 \pm 0.3$ & $36.2 \pm 0.1$ & $36.3 \pm 0.1$ & $36.3 \pm 0.1$ & $36.6 \pm 0.2^{\#}$ \\
\hline Insulin (pmol/L) & $23 \pm 3$ & $18 \pm 3$ & $380 \pm 21$ & $294 \pm 17 * *$ & $27 \pm 5$ & $24 \pm 6$ & $412 \pm 28$ & $362 \pm 21$ * \#\#, † \\
\hline Glucagon (pg/mL) & $58 \pm 14$ & $62 \pm 11$ & $39 \pm 8$ & $38 \pm 6^{\#}$ & $73 \pm 16$ & $78 \pm 15$ & $57 \pm 10$ & $56 \pm 18^{\#}$ \\
\hline Cortisol (ng/mL) & $88 \pm 9$ & $138 \pm 17$ & $94 \pm 11$ & $211 \pm 20 * *$ & $315 \pm 35$ & $315 \pm 31$ & $342 \pm 37$ & $339 \pm 35^{\#}$ \\
\hline $\mathrm{GH}(\mathrm{ng} / \mathrm{mL})$ & $0.38 \pm 0.11$ & $3.01 \pm 0.64$ & $1.05 \pm 0.33$ & $7.20 \pm 2.75^{*}$ & $0.04 \pm 0.02$ & $0.20 \pm 0.12$ & $0.03 \pm 0.02$ & $0.06 \pm 0.03$ \\
\hline Lactate (mmol/L) & $0.81 \pm 0.10$ & $0.84 \pm 0.07$ & $1.04 \pm 0.08$ & $1.26 \pm 0.12^{\#}$ & $0.88 \pm 0.10$ & $0.79 \pm 0.07$ & $1.16 \pm 0.08$ & $1.09 \pm 0.09^{\#}$ \\
\hline $\begin{array}{l}P \text { values calculated by } \\
\text { during the clamp (300 } \\
\text { interaction between ir } \\
B P \text {, blood pressure; HR }\end{array}$ & $60 \mathrm{~min}) .{ }^{*} P<0$ & 5 placebo vs & $\begin{array}{l}S ; * * P<0.001 \\
\text { araction betw }\end{array}$ & insulin/time and & S. & $P<0.001$ & al vs clamp; ${ }^{\dagger}$ & $\begin{array}{l}\text { neasurements } \\
0.05\end{array}$ \\
\hline
\end{tabular}


$(P=0.053)$ (Table 2). Forearm muscle net protein balance (measured with phenylalanine) and local rates of muscle proteolysis and synthesis were similar in both conditions in both groups. Urea fluxes were unaltered in both groups (Table 2).

\section{Glucose metabolism}

EGP was not altered by LPS in CTR, but tended to be decreased by LPS infusion in HP $(P=0.081)$. In HP GIR was significantly decreased by LPS $(5.20 \pm 1.00 \mathrm{mg} / \mathrm{kg} /$ $\min$ (placebo) vs $4.76 \pm 0.91 \mathrm{mg} / \mathrm{kg} / \mathrm{min}$ (LPS), $P=0.015$ ) and remained unaffected in CTR. Arterialized glucose concentrations were similar in both conditions in HP: $5.4 \pm 0.1 \mathrm{mmol} / \mathrm{L}$ (placebo) vs $5.1 \pm 0.1 \mathrm{mmol} / \mathrm{L}$ (LPS), basal period and $4.9 \pm 0.1 \mathrm{mmol} / \mathrm{L}$ (placebo) vs $4.9 \pm 0.1 \mathrm{mmol} / \mathrm{L}$ (LPS), clamp. ANOVA showed no overall LPS effect on glucose concentrations in the two groups, but paired $t$-tests showed a minute decrease in the basal state in CTR: $5.4 \pm 0.1 \mathrm{mmol} / \mathrm{L}$ (placebo) vs $5.1 \pm 0.1 \mathrm{mmol} / \mathrm{L}$ (LPS), basal period, $P=0.009$ (Table 2).

\section{Lipid metabolism}

Arterialized concentrations of FFAs and palmitate were not affected by LPS infusion (Table 2). Palmitate fluxes remained similar in both situations in HP, whereas they were increased by LPS in CTR (ANOVA main LPS effect: $P=0.032$ ): $154 \pm 24 \mu \mathrm{mol} / \mathrm{min}$ (placebo) vs $164 \pm 19 \mu \mathrm{mol} /$ min (LPS), basal period, $P=0.712$ and $39.6 \pm 6.3 \mu \mathrm{mol} /$ $\min$ (placebo) vs $124 \pm 47 \mu \mathrm{mol} / \mathrm{min}$ (LPS), clamp, $P=0.027$ (Fig. 1C, D and Table 2). Likewise, palmitate SA was unaltered in HP, and decreased by LPS infusion in CTR (ANOVA main LPS effect: $P=0.035$ ) (Fig. 1D and F). Significant interaction between LPS and insulin were observed in CTR but not in HP as regards palmitate fluxes $(P=0.025)$ and SA $(P=0.024)$ (Table 2$)$.

\section{Western blotting analysis of muscle biopsies}

Phosphorylation of Thr308, Ser473, AS160 and de-phosphorylation of GS responded to insulin stimulation in both groups with no effect of LPS (Figs 2 and 3).

Phosphorylation of mTOR Ser2448 responded to insulin stimulation in both groups, and tended to increase after LPS in CTR during the basal period. This difference was not present downstream of mTOR at the S6 level, whereas phosphorylation of 4E-BP1 was significantly increased by LPS in CTR during the basal period (Fig. 2). Signaling to protein synthesis was unaltered by LPS in HP (Fig. 3).

\section{AT biopsies mRNA}

Overall TW ANOVA for repeated measurements revealed a main LPS effect to decrease ATGL mRNA in CTR $(P=0.024)$, and post hoc test showed borderline significance during the basal period $(P=0.05)$. In HP there was no overall LPS effect, whereas ATGL mRNA increased with time after LPS and there was significant interaction between LPS and insulin/time (Table 3).

LPS tended to decrease G0S2 mRNA in CTR $(P=0.07)$ and a paired post hoc $t$-test revealed significance during the
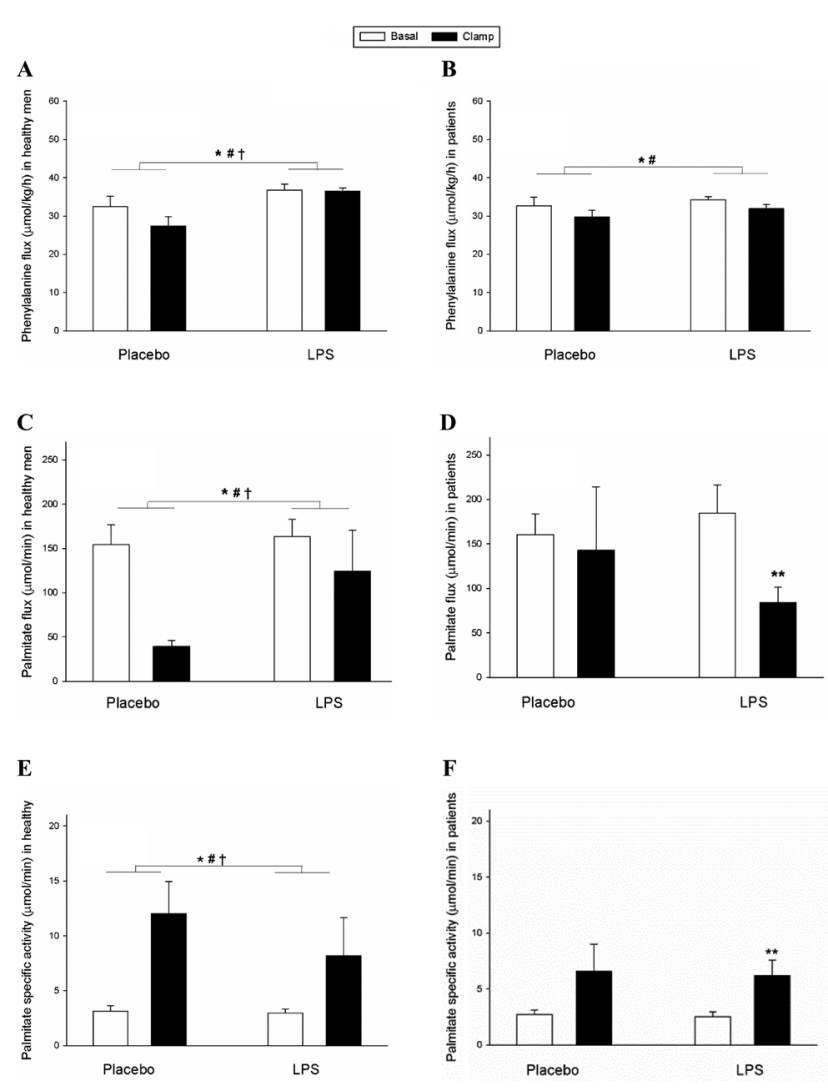

\section{Figure 1}

Phenylalanine and palmitate kinetics in control subjects (CTR) and hypopituitary patients (HP). LPS increased phenylalanine fluxes in both groups, but significantly more so in CTR (A and B). LPS increased whole-body palmitate fluxes and decreased palmitate-specific activity in CTR (C and E), but not in HP (D and F). White bars= basal period, black bars=clamp. Mean values from triplicate sampling at times 160,170 and $180 \mathrm{~min}$ (basal) and 340, 350 and $360 \mathrm{~min}$ (clamp). ${ }^{*} P<0.05$ placebo vs LPS; ${ }^{*} P<0.05$ basal vs clamp. ${ }^{\dagger} P<0.05$ interaction between insulin/time and LPS. ${ }^{*} P<0.05$ basal vs clamp during the LPS day (paired $t$-test). 
clamp $(P=0.031)$. G0S2 mRNA in patients was unaffected by LPS.

HSL, Perilipin and CIDEA mRNA were unaltered in both groups.

\section{Comparison between CTR and HP}

LPS increased cortisol levels in CTR, but not in HP, and the difference between CTR and HP was significant both in basal period $(P=0.004)$ and during the clamp $(P<0.001)$. GH levels were increased in CTR compared with HP (Table 4).

During the clamp phenylalanine fluxes in CTR were increased compared with HP $(P<0.001)$.

Palmitate SA was increased in CTR compared with HP $(P=0.030)$ and fluxes were borderline significantly increased in CTR during the clamp $(P=0.073)$. GOS2 mRNA expression in CTR was decreased compared with HP during the clamp $(P=0.002)$. We did not detect other differences of metabolic indices between groups.

\section{Discussion}

This study was designed to compare the metabolic effects of LPS in HP (without hypothalamo-pituitary ACTH and GH responses) and CTR (with normal stress hormone responses) to test whether infusion of LPS affects glucose, protein and lipid metabolism differentially depending on pituitary function. In line with previous studies, we confirmed that LPS induces increased lipolysis and increased amino acid/protein fluxes in healthy volunteers, and as a novel finding we showed that these effects were significantly blunted in HP.

Our results thus demonstrate two critical metabolic distinctions, that is increased lipolysis and increased amino acid turnover, between CTR with intact pituitary function and HP with pituitary deficiency and highlights the importance of pituitary hormone release in inducing these two metabolic stress responses.

Our study was designed to exploit the fact that HP are devoid of ACTH and GH secretion and thus allow assessment of the role of cortisol and GH during metabolic stress. It is important to underline that cortisol levels were increased $>2$-fold and GH levels $>7$-fold after LPS in CTR subjects whereas cortisol remained unaltered and GH undetectable in HP subjects. It should also be noted that we infused high doses of iv hydrocortisone $(80 \mathrm{mg} / 6 \mathrm{~h})$ to $\mathrm{HP}$ in both settings to prevent serious LPS-induced side effects, rendering our patients hypercortisolemic. It is possible that the outcome would

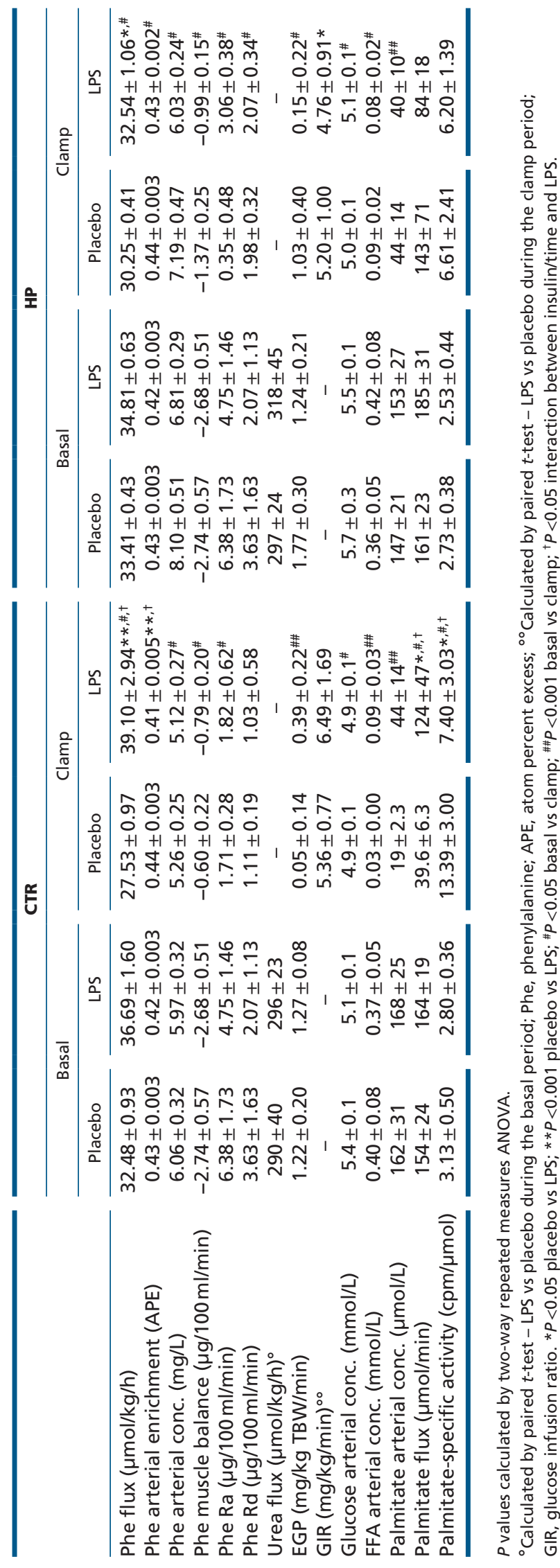

www.eje-online.org 

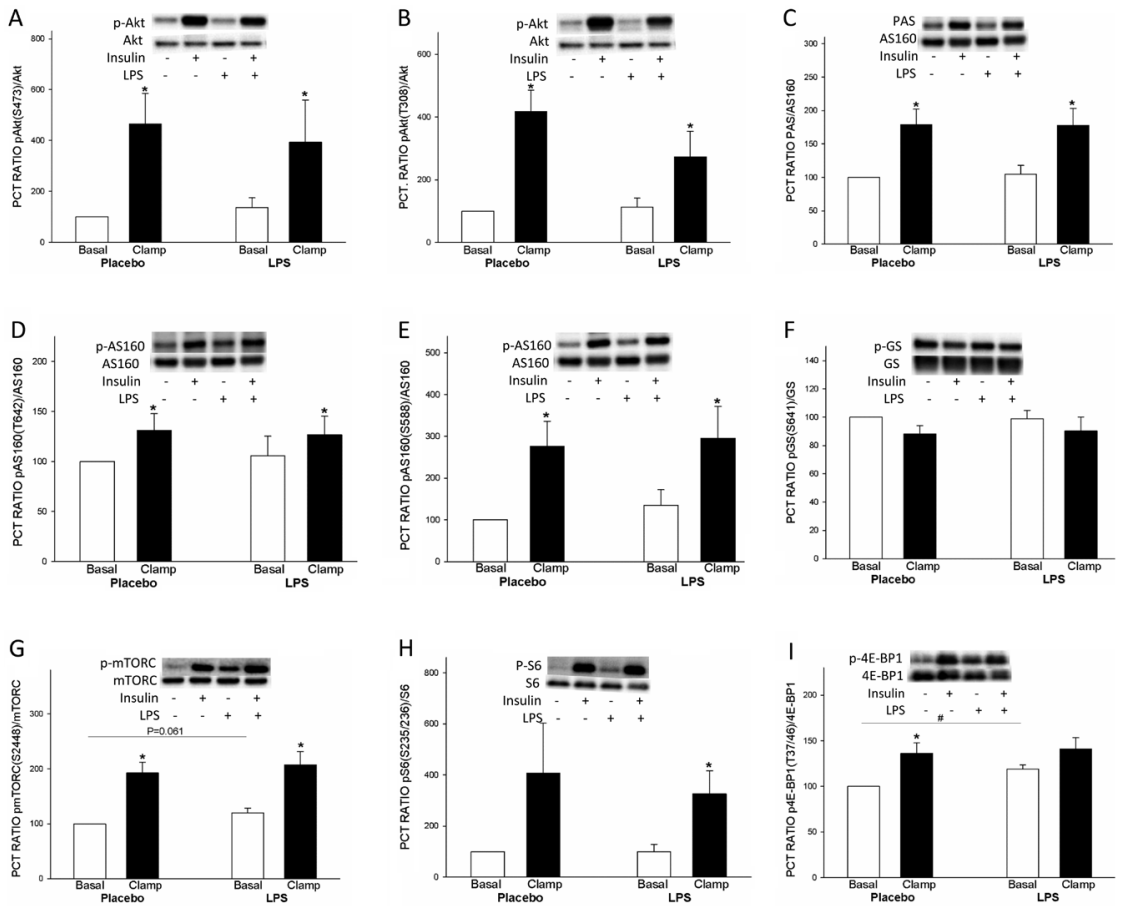

Figure 2

Intramyocellular signaling in control subjects (CTR). Phosphorylation (p) of Thr308 and Ser473 on Akt (A and B), phosphorylation of AS160 Thr642 and Ser588 (C, D, E), de-phosphorylation of GS (F) and phosphorylation of mTOR Ser2448 (G), S6 (H) and 4E-BP1 (I) in muscle biopsies taken before and during a hyperinsulinemic-euglycemic clamp was assessed by Western blotting analysis. Throughout the figure, open bars indicate no insulin stimulation and filled bars indicate insulin stimulation. When possible phosphor blots were stripped and reprobed using alternative phosphor antibodies or antibodies against the unphosphorylated form of the protein. ${ }^{*} P<0.05$ basal vs clamp. ${ }^{\#} P<0.05$ placebo vs LPS during the basal period. have been different, if it had been feasible to conduct the studies with lower levels of cortisol. Nonetheless, our data show that HP patients with fixed low GH levels and high cortisol levels respond differently than control subjects with intact $\mathrm{GH}$ and cortisol responses, thereby implying that the ability to increase GH and cortisol in response to LPS is decisive for a full metabolic response to occur.
Our data showed that palmitate fluxes increased $>3$-fold after $6 \mathrm{~h}$ of LPS exposure in CTR and palmitate SA correspondingly decreased, whereas these parameters remained virtually unaffected in HP. This suggests that increased lipolysis during inflammatory metabolic stress induced by LPS depends on intact GH and cortisol secretion. The lipolytic effects of LPS were
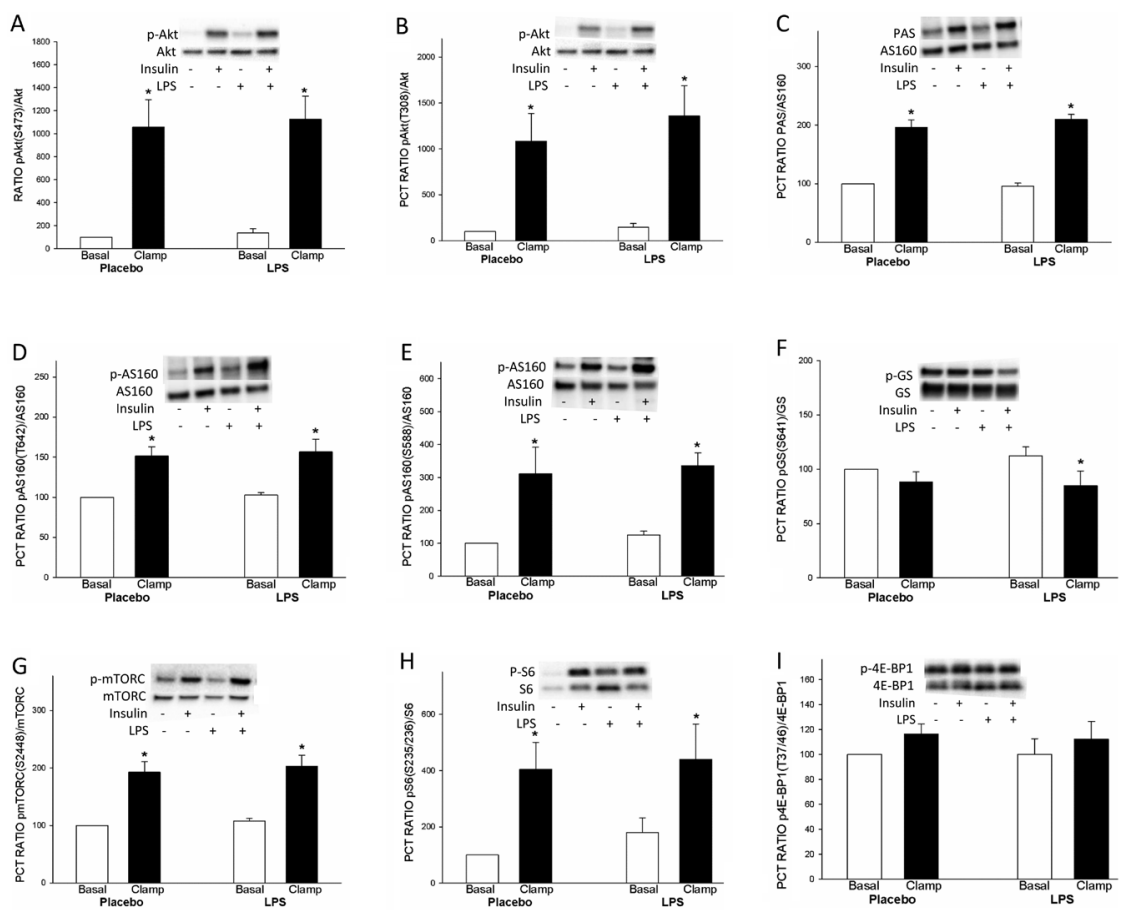

Figure 3

Intramyocellular signaling in hypopituitary patients (HP).

Phosphorylation ( $p$ ) of Thr308 and Ser473 on Akt (A and $B)$, phosphorylation of AS160 Thr642 and Ser588 (C, D, E), de-phosphorylation of GS (F) and phosphorylation of mTOR Ser2448 (G), S6 (H) and 4E-BP1 (I) in muscle biopsies taken before and during a hyperinsulinemic euglycemic clamp was assessed by Western blotting analysis. Throughout the figure, open bars indicate no insulin stimulation and filled bars indicate insulin stimulation. When possible phosphor blots were stripped and reprobed using alternative phosphor antibodies or antibodies against the unphosphorylated form of the protein. ${ }^{*} P<0.05$ basal vs clamp. 
most pronounced after $5-6 \mathrm{~h}$ during the clamp - this is compatible with the fact that both GH and cortisol act after a latency of some hours $(37,42)$. GH and cortisol have been shown to act additively to increase lipolysis in humans (43).

Previous studies in humans have shown substantially increased femoral vein release of free fatty acids $2-6 \mathrm{~h}$ after a systemic LPS bolus in healthy volunteers studied once $(13,28)$ and investigations of the direct lipolytic effect of endotoxin in rodents and in isolated primary adipocytes have reported increased lipolysis and activity and protein levels of HSL and ATGL (28). Furthermore, a recent study using an LPS-infused leg model showed increased net palmitate release and increased tritiated palmitate dilution in the infused leg, indicating that LPS per se is capable of stimulating lipolysis (24). In the AT specimens, we observed a 50\% reduction in G0S2 mRNA in CTR only, an effect which in spite of a slight decrease in ATGL mRNA, may contribute to an overall stimulation of lipolysis. This effect was absent in HP. Human studies investigating the interaction between ATGL, G0S2, LPS and cortisol and GH are sparse. It has been reported that fasting and high levels of GH in humans reduce GOS2 mRNA and protein in AT (44).

After administration of LPS we saw $a \approx 50 \%$ increase in whole-body phenylalanine fluxes in CTR compared with a 5-10\% increase in HP and this increase was more pronounced in CTR indicating a major difference in protein turnover between CTR and HP. Previous studies have shown increased wholebody protein breakdown and increased muscle amino acid release $(20,45,46)$. In our study we failed to observe any major effects of LPS on forearm amino acid metabolism, perhaps because the study designs differedwe used other dosages of LPS and investigated the forearm rather than the leg. Local LPS administration in the leg does not induce detectable alteration of amino acid metabolism (24).

The mechanisms behind the increased protein fluxes catalyzed by LPS are unclear and few studies have addressed the issue. Cortisol and other glucocorticoids exert protein catabolic effects, whereas $\mathrm{GH}$ is an anabolic hormone (47). Glucocorticoids have been reported to decrease mTOR phosphorylation and muscle growth in skeletal muscles of the ovine fetus (48), but this effect could be offset by increased amino acid levels, as observed in our study in HP $(P=0.052)$. In our study, analysis of muscle biopsies revealed increased phosphorylation of $4 \mathrm{E}-\mathrm{BP} 1$, a putative promoter of protein synthesis, in CTR only.

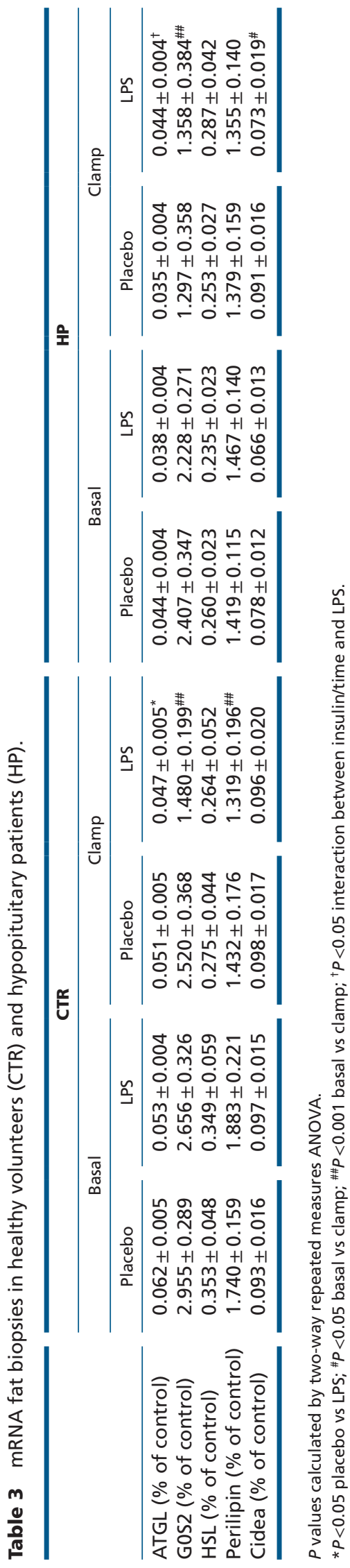


Table 4 Comparison of LPS-induced delta values between healthy volunteers (CTR) and hypopituitary patients (HP).

\begin{tabular}{l}
\hline \\
\hline Cortisol $(\mathrm{ng} / \mathrm{mL})$ \\
GH $(\mathrm{ng} / \mathrm{mL})$ \\
Phe flux $(\mu \mathrm{mol} / \mathrm{kg} / \mathrm{h})$ \\
Palmitate flux $(\mu \mathrm{mol} / \mathrm{min})$ \\
Palmitate-specific activity (cpm/ $\mu \mathrm{mol})$ \\
FFA (mmol/L) \\
GOS2 mRNA (\% of control)
\end{tabular}

\begin{tabular}{|c|c|c|}
\hline \multicolumn{3}{|c|}{ Basal } \\
\hline CTR & HP & $P$ value \\
\hline $50 \pm 16$ & $0 \pm 5.5$ & 0.004 \\
\hline $2.63 \pm 0.62$ & $0.16 \pm 0.11$ & 0.001 \\
\hline $4.2 \pm 1.5$ & $1.4 \pm 0.5$ & 0.110 \\
\hline $10 \pm 24.4$ & $24 \pm 18.1$ & 0.637 \\
\hline $0.33 \pm 0.6$ & $0.2 \pm 0.3$ & 0.838 \\
\hline $0.03 \pm 0.08$ & $0.06 \pm 0.06$ & 0.360 \\
\hline $0.30 \pm 0.36$ & $0.18 \pm 0.15$ & 0.779 \\
\hline
\end{tabular}

\begin{tabular}{|c|c|c|}
\hline \multicolumn{3}{|c|}{ Clamp } \\
\hline CTR & HP & $P$ value \\
\hline $157 \pm 22$ & $3 \pm 7.9$ & $<0.001$ \\
\hline $6.15 \pm 2.92$ & $0.03 \pm 0.02$ & 0.026 \\
\hline $11.6 \pm 0.8$ & $2.3 \pm 0.9$ & $<0.001$ \\
\hline $84 \pm 51.4$ & $59 \pm 77.0$ & 0.073 \\
\hline $6 \pm 1.7$ & $0.41 \pm 1.7$ & 0.030 \\
\hline $0.06 \pm 0.02$ & $0.01 \pm 0.01$ & 0.081 \\
\hline $1.04 \pm 0.28$ & $0.06 \pm 0.08$ & 0.002 \\
\hline
\end{tabular}

$P$ values calculated by $t$-test (delta values LPS placebo) CTR vs HP; Phe, phenylalanine; GH, growth hormone; FFA, free fatty acids.

As regards insulin sensitivity, we, somewhat unexpectedly, observed $\approx 10 \%$ decreased GIR values in HP only (indicating decreased insulin-stimulated glucose disposal), albeit this was not significantly different from CTR. A priori one would predict decreased insulin sensitivity in CTR subjects in whom cortisol and GH levels were increased and lipolytic fluxes raised. On the other hand, local LPS administration also directly induces insulin resistance (24).

In conclusion, our data confirm that LPS induces increased lipolysis and increased amino acid/protein fluxes in CTR. It is a novel finding that in HP there was no increase in lipolysis and less pronounced increases in phenylalanine fluxes, suggesting that these two metabolic processes depend on intact pituitary function and subsequent cortisol and $\mathrm{GH}$ release. In control subjects with intact ACTH and GH responses reduced mRNA expression of the ATGL inhibitor GOS2 may lead to stimulation of lipolysis and activation of the mTOR4E-BP1 path may contribute to increased phenylalanine fluxes.

\section{Declaration of interest}

The authors declare that there is no conflict of interest that could be perceived as prejudicing the impartiality of the research reported.

Funding

This work was supported by the The Lundbeck Foundation, Denmark.

\section{Acknowledgements}

We thank Annette Mengel and Lisa Buus at Aarhus University Hospital, Aarhus, Denmark, for excellent technical assistance.

\section{References}

1 Alexander C \& Rietschel ET. Bacterial lipopolysaccharides and innate immunity. Journal of Endotoxin Research 20017 167-202. (doi:10.1179/ 096805101101532675)
2 Dinarello CA. Infection, fever, and exogenous and endogenous pyrogens: some concepts have changed. Journal of Endotoxin Research 200410 201-222. (doi:10.1179/096805104225006129)

3 Opal SM, Scannon PJ, Vincent JL, White M, Carroll SF, Palardy JE, Parejo NA, Pribble JP \& Lemke JH. Relationship between plasma levels of lipopolysaccharide (LPS) and LPS-binding protein in patients with severe sepsis and septic shock. Journal of Infectious Diseases 1999180 1584-1589. (doi:10.1086/315093)

4 Blaut M \& Klaus S. Intestinal microbiota and obesity. Handbook of Experimental Pharmacology 2012 251-273. (doi:10.1007/978-3-64224716-3_11)

5 Kolb H \& Mandrup-Poulsen T. The global diabetes epidemic as a consequence of lifestyle-induced low-grade inflammation. Diabetologia 201053 10-20. (doi:10.1007/s00125-009-1573-7)

6 Manco M, Putignani L \& Bottazzo GF. Gut microbiota, lipopolysaccharides, and innate immunity in the pathogenesis of obesity and cardiovascular risk. Endocrine Reviews 201031 817-844. (doi:10.1210/er.2009-0030)

7 Cani PD, Amar J, Iglesias MA, Poggi M, Knauf C, Bastelica D, Neyrinck AM, Fava F, Tuohy KM, Chabo C et al. Metabolic endotoxemia initiates obesity and insulin resistance. Diabetes 200756 1761-1772. (doi:10.2337/db06-1491)

8 Lassenius MI, Pietilainen KH, Kaartinen K, Pussinen PJ, Syrjanen J, Forsblom C, Pörsti I, Rissanen A, Kaprio J, Mustonen J et al. Bacterial endotoxin activity in human serum is associated with dyslipidemia, insulin resistance, obesity, and chronic inflammation. Diabetes Care 201134 1809-1815. (doi:10.2337/dc10-2197)

9 Bloesch D, Keller U, Spinas GA, Kury D, Girard J \& Stauffacher W. Effects of endotoxin on leucine and glucose kinetics in man: contribution of prostaglandin E2 assessed by a cyclooxygenase inhibitor. Journal of Clinial Endocrinology and Metabolism $1993 \mathbf{7 7}$ 1156-1163. (doi:10.1210/jcem.77.5.8077306)

10 Michaeli B, Martinez A, Revelly JP, Cayeux MC, Chiolero RL, Tappy L $\&$ Berger MM. Effects of endotoxin on lactate metabolism in humans. Critial Care 201216 R139. (doi:10.1186/cc11444)

11 Agwunobi AO, Reid C, Maycock P, Little RA \& Carlson GL. Insulin resistance and substrate utilization in human endotoxemia. Journal of Clinial Endocrinology and Metabolism 200085 3770-3778. (doi:10.1210/jcem.85.10.6914)

12 van der Crabben SN, Blumer RM, Stegenga ME, Ackermans MT, Endert E, Tanck MW, Serlie MJ, van der Poll T \& Sauerwein HP. Early endotoxemia increases peripheral and hepatic insulin sensitivity in healthy humans. Journal of Clinial Endocrinology and Metabolism 2009 94 463-468. (doi:10.1210/jc.2008-0761)

13 Fong Y, Matthews DE, He W, Marano MA, Moldawer LL \& Lowry SF. Whole body and splanchnic leucine, phenylalanine, and glucose kinetics during endotoxemia in humans. American Journal of Physiology 1994266 R419-R425. (doi:10.1210/jcem.77.5.8077306)

14 Mehta NN, McGillicuddy FC, Anderson PD, Hinkle CC, Shah R, Pruscino L, Tabita-Martinez J, Sellers KF, Rickels MR \& Reilly MP. 
Experimental endotoxemia induces adipose inflammation and insulin resistance in humans. Diabetes 201059 172-181. (doi:10.2337/ db09-0367)

15 Mehta NN, Heffron SP, Patel PN, Ferguson J, Shah RD, Hinkle CC, Krishnamoorthy P, Shah R, Tabita-Martinez J, Terembula K et al. A human model of inflammatory cardio-metabolic dysfunction; a double blind placebo-controlled crossover trial. Journal of Translational Medicine 201210 124. (doi:10.1186/1479-5876-10-124)

16 Sakamoto K \& Holman GD. Emerging role for AS160/TBC1D4 and TBC1D1 in the regulation of GLUT4 traffic. American Journal of Physiology: Endocrinology and Metabolism 2008295 E29-E37. (doi:10.1152/ajpcell.00466.2007)

17 Karlsson HK, Zierath JR, Kane S, Krook A, Lienhard GE \& WallbergHenriksson H. Insulin-stimulated phosphorylation of the Akt substrate AS160 is impaired in skeletal muscle of type 2 diabetic subjects. Diabetes 200554 1692-1697. (doi:10.2337/diabetes.54.6.1692)

18 Nielsen JN \& Wojtaszewski JF. Regulation of glycogen synthase activity and phosphorylation by exercise. Proceedings of the Nutrition Society 200463 233-237. (doi:10.1079/PNS2004348)

19 Nikoulina SE, Ciaraldi TP, Mudaliar S, Mohideen P, Carter L \& Henry RR. Potential role of glycogen synthase kinase-3 in skeletal muscle insulin resistance of type 2 diabetes. Diabetes 200049 263-271. (doi:10.2337/diabetes.49.2.263)

20 Vesali RF, Cibicek N, Jakobsson T, Klaude M, Wernerman J \& Rooyackers O. Protein metabolism in leg muscle following an endotoxin injection in healthy volunteers. Clinical Science 2010118 421-427. (doi:10.1042/CS20090332)

21 Evans WJ, Morley JE, Argiles J, Bales C, Baracos V, Guttridge D, Jatoi A, Kalantar-Zadeh K, Lochs H, Mantovani G et al. Cachexia: a new definition. Clinical Nutrition 200827 793-799. (doi:10.1016/ j.clnu.2008.06.013)

22 Zoncu R, Efeyan A \& Sabatini DM. mTOR: from growth signal integration to cancer, diabetes and ageing. Nature Reviews Molecular Cell Biology 201112 21-35. (doi:10.1038/nrm3025)

23 Wellhoener P, Vietheer A, Sayk F, Schaaf B, Lehnert H \& Dodt C. Metabolic alterations in adipose tissue during the early phase of experimental endotoxemia in humans. Hormone and Metabolic Research 201143 754-759. (doi:10.1055/s0031-1287854)

24 Buhl M, Bosnjak E, Vendelbo MH, Gjedsted J, Nielsen RR, Hafstrom T, Vestergaard ET, Jessen N, Tønnesen E, Møller AB et al. Direct effects of locally administered lipopolysaccharide on glucose, lipid, and protein metabolism in the placebo-controlled, bilaterally infused human leg. Journal of Clinial Endocrinology and Metabolism 201398 2090-2099. (doi:10.1210/jc.2012-3836)

25 Zimmermann R, Strauss JG, Haemmerle G, Schoiswohl G, Birner-Gruenberger R, Riederer M, Lass A, Neuberger G, Eisenhaber F, Hermetter A et al. Fat mobilization in adipose tissue is promoted by adipose triglyceride lipase. Science 2004306 1383-1386. (doi:10.1126/ science.1100747)

26 Haemmerle G, Zimmermann R, Hayn M, Theussl C, Waeg G, Wagner E, Sattler W, Magin TM, Wagner EF \& Zechner R. Hormone-sensitive lipase deficiency in mice causes diglyceride accumulation in adipose tissue, muscle, and testis. Journal of Biological Chemistry 2002277 4806-4815. (doi:10.1074/jbc.M110355200)

27 Yang X, Lu X, Lombes M, Rha GB, Chi YI, Guerin TM, Smart EJ \& Liu J. The $G(0) / G(1)$ switch gene 2 regulates adipose lipolysis through association with adipose triglyceride lipase. Cell Metabolism 201011 194-205. (doi:10.1016/j.cmet.2010.02.003)

$28 \mathrm{Zu} \mathrm{L}$, He J, Jiang H, Xu C, Pu S \& Xu G. Bacterial endotoxin stimulates adipose lipolysis via toll-like receptor 4 and extracellular signal-regulated kinase pathway. Journal of Biological Chemistry 2009 284 5915-5926. (doi:10.1074/jbc.M807852200)

29 Grisouard J, Bouillet E, Timper K, Radimerski T, Dembinski K, Frey DM, Peterli R, Zulewski H, Keller U, Müller B et al. Both inflammatory and classical lipolytic pathways are involved in lipopolysaccharide-induced lipolysis in human adipocytes. Innate Immunity 201218 25-34. (doi:10.1177/1753425910386632)

30 Nielsen TS, Kampmann U, Nielsen RR, Jessen N, Orskov L, Pedersen SB, Jørgensen JO, Lund S \& Møller N. Reduced mRNA and protein expression of perilipin A and G0/G1 switch gene 2 (GOS2) in human adipose tissue in poorly controlled type 2 diabetes. Journal of Clinial Endocrinology and Metabolism 201297 E1348-E1352. (doi:10.1210/jc.2012-1159)

31 van der Poll T, Romijn JA, Endert E, Borm JJ, Buller HR \& Sauerwein HP. Tumor necrosis factor mimics the metabolic response to acute infection in healthy humans. American Journal of Physiology 1991261 E457-E465.

32 van HG, Steensberg A, Sacchetti M, Fischer C, Keller C, Schjerling P, Hiscock N, Møller K, Saltin B, Febbraio MA et al. Interleukin-6 stimulates lipolysis and fat oxidation in humans. Journal of Clinial Endocrinology and Metabolism 200388 3005-3010. (doi:10.1210/ jc.2002-021687)

33 Taudorf S, Krabbe KS, Berg RM, Pedersen BK \& Møller K. Human models of low-grade inflammation: bolus vs continuous infusion of endotoxin. Clinical and Vaccine Immunology 200714 250-255. (doi:10.1128/CVI.00380-06)

34 Soop M, Duxbury H, Agwunobi AO, Gibson JM, Hopkins SJ, Childs C, Cooper RG, Maycock P, Little RA \& Carlson GL. Euglycemic hyperinsulinemia augments the cytokine and endocrine responses to endotoxin in humans. American Journal of Physiology: Endocrinology and Metabolism 2002282 E1276-E1285. (doi:10.1152/ ajpendo.00535.2001)

35 Williams PN, Collier CT, Carroll JA, Welsh TH Jr \& Laurenz JC. Temporal pattern and effect of sex on lipopolysaccharideinduced stress hormone and cytokine response in pigs. Domestic Animal Endocrinology 200937 139-147. (doi:10.1016/j. domaniend.2009.04.004)

36 Christiansen JJ, Djurhuus CB, Gravholt CH, Iversen P, Christiansen JS, Schmitz O, Weeke J, Jørgensen JO \& Møller N. Effects of cortisol on carbohydrate, lipid, and protein metabolism: studies of acute cortisol withdrawal in adrenocortical failure. Journal of Clinial Endocrinology and Metabolism 200792 3553-3559. (doi:10.1210/jc.2007-0445)

37 Møller N \& Jørgensen JO. Effects of growth hormone on glucose, lipid, and protein metabolism in human subjects. Endocrine Reviews 200930 152-177. (doi:10.1210/er.2008-0027)

38 Tavernier G, Barbe P, Galitzky J, Berlan M, Caput D, Lafontan M \& Langin D. Expression of beta3-adrenoceptors with low lipolytic action in human subcutaneous white adipocytes. Journal of Lipid Research $19963787-97$.

39 Smith IJ, Alamdari N, O’Neal P, Gonnella P, Aversa Z \& Hasselgren PO. Sepsis increases the expression and activity of the transcription factor Forkhead Box O 1 (FOXO1) in skeletal muscle by a glucocorticoiddependent mechanism. International Journal of Biochemistry and Cell Biology 201042 701-711. (doi:10.1016/j.biocel.2010.01.006)

40 Steele R. Influences of glucose loading and of injected insulin on hepatic glucose output. Annals of the New York Academy of Sciences 195982 420-430. (doi:10.1111/j.1749-6632.1959.tb44923.x)

41 Gurtler A, Kunz N, Gomolka M, Hornhardt S, Friedl AA, McDonald K, Kohn JE \& Posch A. Stain-Free technology as a normalization tool in Western blot analysis. Analytical Biochemistry 2013433 105-111. (doi:10.1016/j.ab.2012.10.010)

42 Djurhuus CB, Gravholt CH, Nielsen S, Mengel A, Christiansen JS, Schmitz OE \& Møller N. Effects of cortisol on lipolysis and regional interstitial glycerol levels in humans. American Journal of Physiology: Endocrinology and Metabolism 2002283 E172-E177. (doi:10.1152/ ajpendo.00544.2001)

43 Djurhuus CB, Gravholt CH, Nielsen S, Pedersen SB, Møller N \& Schmitz O. Additive effects of cortisol and growth hormone on regional and systemic lipolysis in humans. American Journal of Physiology: Endocrinology and Metabolism 2004286 E488-E494. 
44 Nielsen TS, Vendelbo MH, Jessen N, Pedersen SB, Jørgensen JO, Lund S \& Møller N. Fasting, but not exercise, increases adipose triglyceride lipase (ATGL) protein and reduces $\mathrm{G}(0) / \mathrm{G}(1)$ switch gene 2 (GOS2) protein and mRNA content in human adipose tissue. Journal of Clinial Endocrinology and Metabolism 201196 E1293-E1297. (doi:10.1210/jc.2011-0149)

45 Fong YM, Marano MA, Moldawer LL, Wei H, Calvano SE, Kenney JS, Allison AC, Cerami A, Shires GT \& Lowry SF. The acute splanchnic and peripheral tissue metabolic response to endotoxin in humans. Journal of Clinical Investigation 199085 1896-1904. (doi:10.1172/JCI114651)

46 Vesali RF, Klaude M, Rooyackers O \& Wernerman J. Amino acid metabolism in leg muscle after an endotoxin injection in healthy volunteers. American Journal of Physiology: Endocrinology and Metabolism 2005288 E360-E364. (doi:10.1152/ajpcell. 00386.2004)

47 Horber FF \& Haymond MW. Human growth hormone prevents the protein catabolic side effects of prednisone in humans. Journal of Clinical Investigation 199086 265-272. (doi:10.1172/ JCI114694)

48 Jellyman JK, Martin-Gronert MS, Cripps RL, Giussani DA, Ozanne SE, Shen QW, Du M, Fowden AL \& Forhead AJ. Effects of cortisol and dexamethasone on insulin signalling pathways in skeletal muscle of the ovine fetus during late gestation. PLoS ONE 20127 e52363. (doi:10.1371/journal.pone.0052363)

Received 24 May 2016

Revised version received 1 August 2016

Accepted 24 August 2016 